\title{
Prognostic value of preoperative low bone mineral density in patients with digestive cancers: a systematic review and meta-analysis
}

\author{
Jun Watanabe ${ }^{1} \cdot$ Akihiro Saitsu $^{2} \cdot$ Atsushi Miki $^{1} \cdot$ Kazuhiko Kotani $^{2} \cdot$ Naohiro Sata $^{1}$
}

Received: 27 September 2021 / Accepted: 30 December 2021 / Published online: 11 February 2022

(c) The Author(s) 2022

\begin{abstract}
Purpose Osteopenia typically presents low bone mineral density (BMD) and has recently been reported as a prognostic factor in various cancers. However, the prognostic value of osteopenia in digestive tract cancers remains to be defined. We aimed to review the prognostic value of preoperative osteopenia in patients with digestive cancers.

Methods Cohort studies evaluating the prognostic value of preoperative osteopenia in digestive cancers (colorectal, esophageal, hepatic, bile duct, and pancreatic cancer) were searched using electronic databases and trial registries. The exposure was defined as low BMD estimated by computed tomography at $11^{\text {th }}$ thoracic vertebra, while comparator was normal BMD. The primary outcomes were overall survival and recurrence-free survival for osteopenia. Random effect meta-analyses were performed. The Grading of Recommendations, Assessment, Development, and Evaluation approach was used to assess the certainty of evidence. Results A total of 11 studies (2230 patients) were included. Osteopenia was an independent risk factor for overall survival (hazard ratio $[\mathrm{HR}]=2.02,95 \% \mathrm{CI}=1.47$ to $2.78 ; I^{2}=74 \%$ ), along with sarcopenia. Osteopenia also predicted poor recurrence-free survival ( $\mathrm{HR}=1.96,95 \% \mathrm{CI}=1.36$ to $\left.2.81 ; I^{2}=85 \%\right)$. In subgroup analyses, osteopenia predicted prognosis in colorectal, esophageal, hepatic, and bile duct cancers, but not in pancreatic cancer. The certainty of the evidence was low due to inconsistency and publication bias.

Conclusion Osteopenia may be independently associated with poor prognosis in patients with digestive tract cancer. Further studies are needed to establish the relevance of osteopenia in the operative prognosis of these patients.
\end{abstract}

Keywords Bone mineral density $\cdot$ Digestive system neoplasms $\cdot$ Meta-analysis $\cdot$ Mortality $\cdot$ Osteopenia $\cdot$ Prognosis $\cdot$ Recurrence $\cdot$ Systematic review

Abbreviations
BMD $\quad$ Bone mineral density
CI $\quad$ Confidence interval

Jun Watanabe

m06105jw@jichi.ac.jp

Akihiro Saitsu

m07039as@jichi.ac.jp

Atsushi Miki

amiki@jichi.ac.jp

Kazuhiko Kotani

kazukotani@jichi.ac.jp

Naohiro Sata

sata2018@jichi.ac.jp

1 Department of Surgery, Division of Gastroenterological, General and Transplant Surgery, Jichi Medical University, Shimotsuke-City, Tochigi 329-0498, Japan

2 Division of Community and Family Medicine, Jichi Medical University, Shimotsuke-City, Tochigi, Japan

$\begin{array}{ll}\text { CT } & \text { Computed tomography } \\ \text { DXA } & \begin{array}{l}\text { Dual-energy x-ray absorptiometry } \\ \text { Grading of Recommendations Assessment, } \\ \text { GRADE }\end{array} \\ \text { HR } & \begin{array}{l}\text { Development, and Evaluation } \\ \text { Hazard ratio }\end{array} \\ \text { OS } & \text { Overall survival } \\ \text { PRISMA } & \begin{array}{l}\text { The Preferred Reporting Items for Systematic } \\ \text { Review and Meta-Analysis }\end{array} \\ \text { RFS } & \text { Recurrence-free survival }\end{array}$

\section{Introduction}

Digestive tract organs, including esophageal, gastric, colon, pancreatic, and hepatic organs, can develop cancers; digestive tract cancer is a leading cause of cancer-related mortality worldwide [1]. The prognosis of most of digestive tract cancers is unfavorable and unsatisfactory [2]. Tumor factors such as tumor size, number, and metastasis are important 
determinants of prognosis for patients with digestive tract cancers, but patient-level factors can have a significant impact on prognosis [3]. As a patient-level factor, sarcopenia has been shown to be a poor prognostic factor in patients who underwent surgery for digestive tract cancers, such as esophageal, gastric, colon, pancreatic, and hepatic cancers $[4,5]$.

Osteopenia, a condition of low bone mineral density (BMD), is another important patient-level factor in cancer treatment because low BMD is associated with a higher risk of falls, fractures, institutionalization, and death, negatively impacting health-related quality of life, and ultimately, the prognosis [6]. A previous study demonstrated that low BMD, a surrogate marker for osteopenia, was an independent risk factor for poor prognosis that precedes sarcopenia [7]. Computed tomography (CT)-derived BMD assessment correlates with dual-energy X-ray absorptiometry (DXA), the gold standard for osteoporosis diagnosis [8], with BMD being analyzed by measuring the mean pixel density of the thoracic vertebral trabeculae on preoperative CT [9]. Although the prognostic value of preoperative osteopenia in patients with digestive tract cancers has been reported [7, 10-13], no systematic review of osteopenia has been performed in these patients.

We hypothesized that preoperative osteopenia (indicative of low BMD) could have a negative impact on longterm outcomes in patients who underwent surgery for digestive tract cancers. Thus, the aim of this study was to review the prognostic value of preoperative osteopenia in patients who underwent resection for digestive tract cancers. Our study also included sarcopenia, knowing that the relevance of osteopenia on prognosis was independent of sarcopenia. This is because sarcopenia (which is a pathology of decreased muscles) can coexists in osteopenic conditions as named osteosarcopenia [10].

\section{Methods}

\section{Protocol and registration}

The results of the present review are presented according to the Preferred reporting Items for Systematic Review and Meta-analysis (PRISMA) 2020 [11]. This protocol was registered in PROSPERO (https://www.crd.york.ac.uk/prospero/).

\section{Inclusion criteria of the articles for the review}

Studies were included using the PECO framework: participant, exposure, comparator, and outcome. The participants were patients who underwent surgery for digestive tract cancer (esophageal, gastric, colorectal, liver, pancreatic, biliary tract, and gallbladder cancer). Each digestive tract cancer (esophageal, gastric, colorectal, liver, pancreatic, biliary tract, and gallbladder cancer) was pathologically diagnosed. The exposure was the presence of preoperative osteopenia defined as preoperative BMD calculated as the average pixel density (HU) within a circle in the midvertebral core at the bottom of the $11^{\text {th }}$ thoracic vertebra on preoperative computed tomography. This assessment correlates with DXA, the gold standard for osteoporosis diagnosis $[8,9]$. The cutoff values for BMD were adopted via comparison with those of healthy adults or DXA values, and the original authors' own cutoff values were also accepted. The comparators were preoperative normal BMD. The primary outcomes were overall survival (OS) and recurrence-free survival (RFS) for osteopenia. The secondary outcome was the OS for sarcopenia. Sarcopenia was diagnosed according to body composition (using computed tomography, DXA, and bioelectrical impedance) or by the European Working Group on Sarcopenia in Older People 2 guidelines [4]. No language, country, observation period, or publication year restrictions were applied. Reviews and case series or reports were excluded.

\section{Search method}

The electronic databases of MEDLINE (PubMed), the Cochrane Central Register of Controlled Trials (Cochrane Library), and EMBASE (Dialog) (Appendix 1), and trial registries in the World Health Organization International Clinical Trials Platform Search Portal (ICTRP), and ClinicalTr ials.gov (Appendix 2) were searched until August 9, 2021. The reference lists of studies, including international guidelines [12] as well as the reference lists of eligible studies, and articles citing eligible studies were checked. The original authors were asked for unpublished or additional data.

\section{Data collection and analysis}

Two reviewers (JW and AS) independently screened the studies based on the inclusion and exclusion criteria and extracted data from the eligible studies. Any disagreements between the two reviewers were resolved by discussion, with disagreements being resolved by a third reviewer acting as an arbiter (KK). Two reviewers (JW and AS) independently evaluated the risk of bias using the Quality In Prognosis Studies tool [13, 14].

Random-effects meta-analyses were performed using Review Manager software (RevMan 5.4.2). Hazard ratios (HRs) and 95\% confidence intervals (CIs) for OS and RFS were pooled. Statistical heterogeneity was evaluated using visual inspection of the forest plots and calculating the $I^{2}$ statistic ( $I^{2}$ values of 0 to $40 \%$ : might not be important; 30 to 60\%: may represent moderate heterogeneity; 50 to $90 \%$ : may represent substantial heterogeneity; 75 to $100 \%$ : considerable heterogeneity) [15]. Publication bias was investigated by searching for unpublished trials using the clinical trial 
registry system (ClinicalTrials.gov and ICTRP). To assess the outcome reporting bias, we compared the outcomes defined in the trial protocols with the outcomes reported in the publications. Potential publication bias was assessed by visual inspection of the funnel plot and Egger's test according to the Cochrane handbook [15]. Subgroup analyses were performed for each cancer type. Sensitivity analysis planned in our protocol could not be performed because of the lack of studies using imputed statistics.

Two reviewers (JW and AS) evaluated the certainty of evidence using the five Grading of Recommendations Assessment, Development, and Evaluation (GRADE) considerations of within- and across-study risk of bias (limitations in the study design and execution or methodological quality), inconsistency (or heterogeneity), indirectness of evidence, and imprecision of the effect estimates and risk of publication bias [16]. Disagreements between the two reviewers were discussed and resolved with a third reviewer (KK) acting as an arbiter, if necessary. A summary of findings table was made for the outcomes based on the Cochrane handbook [15].

\section{Results}

Figure 1 illustrates the process of the study selection. After screening 1072 records, we retained 16 studies for full-text reading. Three studies were excluded because one study had an incorrect population [17], and the other two were incorrect exposures $[18,19]$. Three additional studies were excluded because missing data could not be obtained after asking the original authors [20-22]. After contacting the original authors, we included an additional study. Finally, 11 studies (2230 patients) were included for the meta-analysis [23-33].

Table 1 shows the characteristics of the included studies [23-33]. Of the 11 studies, three studies focused on pancreatic cancer [25, 26, 28], two on colorectal liver metastases $[29,30]$, two on extrahepatic cholangiocarcinoma [24, 32], one on esophageal cancer [31], one on colon cancer [33], and two on hepatocellular carcinoma [23,27]. Six studies adopted cutoff values for BMD from previous studies [23, $25,33,27-29]$, while the other five studies adopted their own cutoff values [24, 26, 30-32]. There was no statistically significant difference in the association between low BMD and normal BMD in five studies where patients received neoadjuvant chemotherapy [25, 26, 29-31]. The risk of bias for study participation, study attrition, outcome measurements, and statistical analysis were low. The risk of bias for prognostic factor measurement was moderate in five studies as they had their own BMD cutoff values [24, 26, 30-32].

\section{Prognostic value of preoperative low BMD in patients with digestive tract cancers}

Table 2 summarizes the findings using the GRADE approach. The certainty of the evidence was low to moderate due to inconsistency and publication bias.

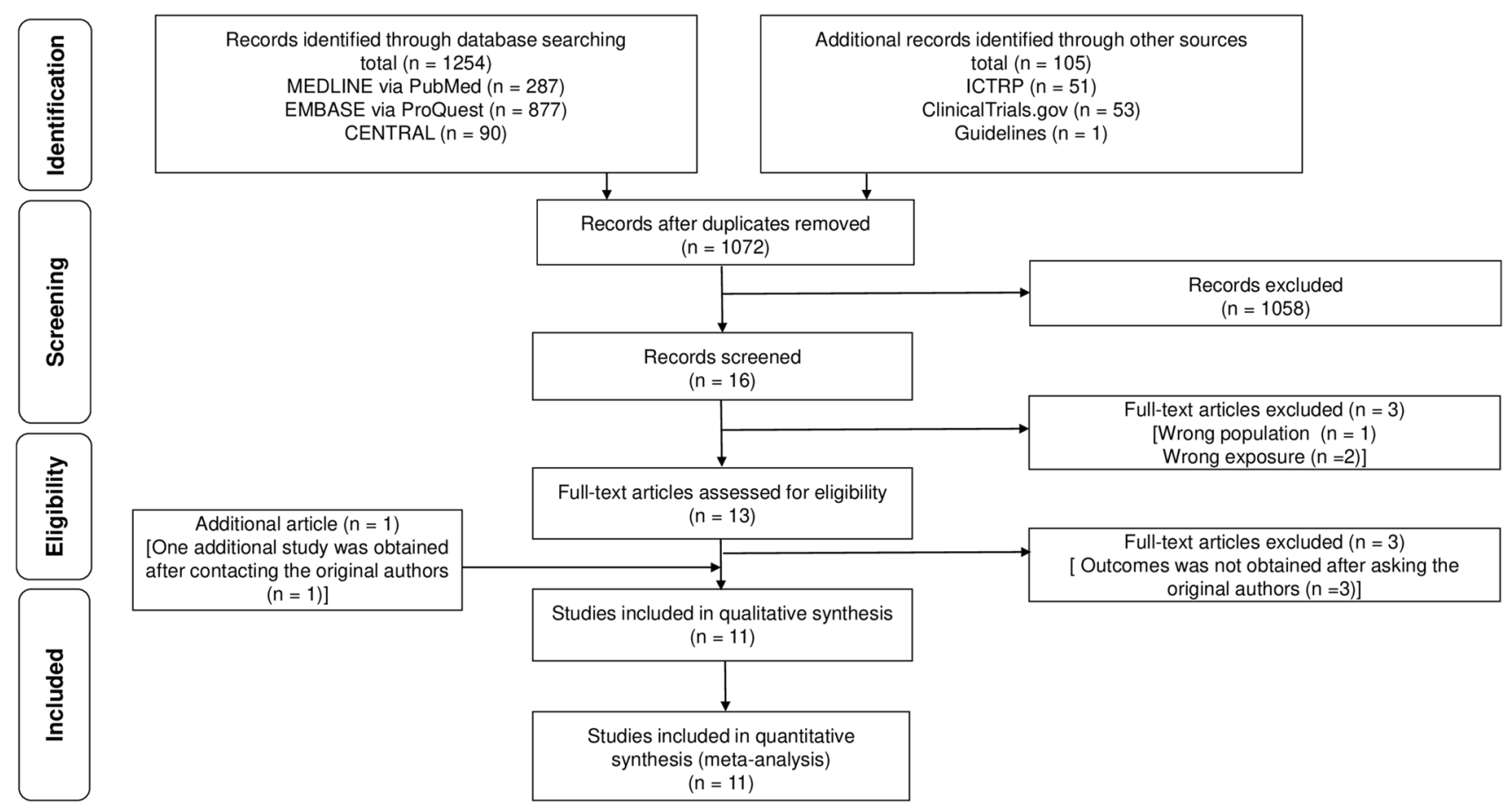

Fig. 1 Flow of the study selection process 
Table 1 The characteristics of the included studies

\begin{tabular}{|c|c|c|c|c|c|c|c|c|c|}
\hline $\begin{array}{l}\text { Authors } \\
\text { [ref no.] }\end{array}$ & Year & Cancer type & Subject no. & Age & Osteopenia no. (\%) & $\begin{array}{l}\text { Cutoff values of BMD } \\
\text { (HU) (male/female) }\end{array}$ & $\begin{array}{l}\text { Neoadjuvant } \\
\text { chemotherapy } \\
\text { no. }(\%)\end{array}$ & Sarcopenia & QUIPS \\
\hline Miyachi [23] & 2019 & $\mathrm{HCC}$ & 465 & 69 & $273(59)$ & 160 & NR & PMI & Low \\
\hline Yao [24] & 2019 & ECC & 181 & 68 & $124(69)$ & 169 & NR & PMI & Moderate \\
\hline Motomura [25] & 2020 & $\mathrm{PC}$ & 91 & 75 & $34(37)$ & $\begin{array}{r}308.82-2.49 * \text { age / } \\
311.84-2.41 * \text { age }\end{array}$ & 4/91 (4) & SMI & Low \\
\hline Sharshar [26] & 2020 & $\mathrm{PC}$ & 275 & 71 & $136(50)$ & $137.5 / 128.8$ & $32 / 275(11)$ & PMI & Moderate \\
\hline Toshima [27] & 2020 & $\mathrm{HCC}$ & 193 & 58 & $103(53)$ & $\begin{array}{r}308.82-2.49 * \text { age / } \\
311.84-2.41 * \text { age }\end{array}$ & NR & SMA & Low \\
\hline Abe [28] & 2021 & $\mathrm{PC}$ & 56 & 72 & $27(48)$ & 160 & $0 / 56(0)$ & SMI & Low \\
\hline Furukawa [29] & 2021 & CRLM & 118 & 68 & $66(56)$ & $\begin{array}{r}308.82-2.49 * \text { age / } \\
311.84-2.41^{*} \text { age }\end{array}$ & $41 / 118(35)$ & PMA & Low \\
\hline Ikuta [30] & 2021 & CRLM & 281 & 66 & $143(51)$ & 141 & $168 / 281(60)$ & NR & Moderate \\
\hline Takahashi [31] & 2021 & $\mathrm{EC}$ & 229 & 68 & $70(31)$ & 122.23 & $127 / 229(55)$ & SMI & Moderate \\
\hline Tamura [32] & 2021 & ECC & 111 & 72 & $8(7)$ & $75 / 74$ & NR & SMI & Moderate \\
\hline Kamada [33] & 2021 & $\mathrm{CC}$ & 230 & 67 & $43(19)$ & $\begin{array}{l}308.82-2.49 * \text { age / } \\
311.84-2.41 * \text { age }\end{array}$ & NR & SMI & Low \\
\hline
\end{tabular}

$B M D$ bone mineral density, $C C$ colon cancer, $C R L M$ colorectal liver metastases, $E C C$ extrahepatic cholangiocarcinoma, $H C C$ hepatocellular carcinoma liver transplant donor, $N R$ not reported, $P C$ pancreatic cancer, $P M I$ psoas muscle index, QUIPS the Quality In Prognosis Studies, SMA skeletal muscle area, $S M I$ skeletal muscle index

\section{OS for low BMD}

OS for low BMD was measured in 11 studies. Low BMD was a significant risk factor for OS $(\mathrm{HR}=2.02$, $95 \% \mathrm{CI}=1.47$ to $2.78 ; \mathrm{I}^{2}=74 \%$ ) (Fig. 2). Subgroup analysis of cancer types showed significant differences $(p=0.007)$. Low BMD in colorectal cancer $(\mathrm{HR}=5.10$, $95 \% \mathrm{CI}=2.72$ to 9.56 ), colorectal liver metastases (HR
$=1.49,95 \% \mathrm{CI}=1.13$ to $\left.1.97 ; I^{2}=0 \%\right)$, esophageal cancer $(\mathrm{HR}=2.24,95 \% \mathrm{CI}=1.42$ to 3.54$)$, extrahepatic cholangiocarcinoma $(\mathrm{HR}=2.54,95 \% \mathrm{CI}=1.51$ to $\left.4.25 ; I^{2}=0 \%\right)$, and hepatocellular carcinoma (HR = $1.55,95 \% \mathrm{CI}=1.17$ to $2.06 ; I^{2}=6 \%$ ) were a significant risk factor for OS, while low BMD in pancreatic cancer $\left(\mathrm{HR}=2.35,95 \% \mathrm{CI}=0.62\right.$ to $\left.8.98 ; I^{2}=76 \%\right)$ was not significant.

Table 2 Summary of findings

Prognostic value of preoperative osteopenia in patients with digestive cancers

Patients: patients with digestive cancers, Exposure: Osteopenia, Comparison: Non-osteopenia

Outcomes

Relative effect $(95 \%$ CI) Patient num- Certainty of

ber (studies) the evidence

Comments

(GRADE)

\begin{tabular}{|c|c|c|c|c|}
\hline Overall survival for osteopenia & $\begin{array}{l}\text { HR } 2.02 \\
\text { (1.47 to } 2.78)\end{array}$ & $\begin{array}{l}2230 \\
\text { (11 studies) }\end{array}$ & Low ${ }^{a, b}$ & Osteopenia may reduce overall survival. \\
\hline Recurrent-free survival for osteopenia & $\begin{array}{l}\text { HR } 1.96 \\
\text { (1.36 to } 2.81)\end{array}$ & $\begin{array}{l}2037 \\
\text { (10 studies) }\end{array}$ & Low ${ }^{a, b}$ & $\begin{array}{l}\text { Osteopenia may reduce recurrent-free } \\
\text { survival. }\end{array}$ \\
\hline Overall survival for sarcopenia & $\begin{array}{l}\text { HR } 1.73 \\
\text { (1.26 to } 2.38)\end{array}$ & $\begin{array}{l}1665 \\
\text { (8 studies) }\end{array}$ & Moderate $^{\mathrm{a}}$ & Sarcopenia likely reduce overall survival. \\
\hline
\end{tabular}

GRADE Working Group grades of evidence; High certainty: We are very confident that the true effect lies close to that of the estimated effect. Moderate certainty: We are moderately confident in the estimated effect. The true effect is likely to be close to the estimated effect, but there is a possibility that it is substantially different. Low certainty: Our confidence in the estimated effect is limited: The true effect may be substantially different from the estimated effect. Very low certainty: We have very little confidence in the estimated effect. The true effect is likely to be substantially different from the estimated effect

Abbreviations: $C I$ confidence interval, $H R$ hazard ratio

${ }^{a}$ Downgraded one point as inconsistency due to substantial heterogeneity

${ }^{\mathrm{b}}$ Downgraded one point as publication bias due to high publication bias 


\section{RFS for low BMD}

The RFS for low BMD was measured in ten studies. Low BMD was a significant risk factor for RFS $(H R=1.96$, $95 \% \mathrm{CI}=1.36$ to $2.81 ; I^{2}=85 \%$ ) (Fig. 3 ). Subgroup analysis of cancer types showed a significant difference $(p<0.00001)$. Low BMD in colon cancer $(\mathrm{HR}=6.75$, $95 \% \mathrm{CI}=3.62$ to 12.56 ), colorectal liver metastases (HR $=1.30,95 \% \mathrm{CI}=1.02$ to $1.66 ; I^{2}=0 \%$ ), esophageal cancer $(\mathrm{HR}=1.74,95 \% \mathrm{CI}=1.15$ to 2.62$)$, and extrahepatic cholangiocarcinoma ( $\mathrm{HR}=3.54,95 \% \mathrm{CI}=2.17$ to 5.78 ; $I^{2}=0 \%$ ) were significant risk factors for RFS, while low $\mathrm{BMD}$ in hepatocellular carcinoma $(\mathrm{HR}=1.08,95 \% \mathrm{CI}=$ 0.86 to 1.35$)$ and pancreatic cancer $(\mathrm{HR}=1.83,95 \% \mathrm{CI}$ $=0.72$ to $4.67 ; I^{2}=83 \%$ ) were not significant.

\section{OS for sarcopenia}

The OS for sarcopenia was measured in eight studies. Sarcopenia was a significant risk factor for OS (HR = $1.73,95 \% \mathrm{CI}=1.26$ to $2.38 ; I^{2}=60 \%$ ) (Fig. 4). Subgroup analysis of cancer types showed significant differences $(p$ $=0.03)$. Sarcopenia in esophageal cancer $(\mathrm{HR}=2.84$, $95 \% \mathrm{CI}=1.65$ to 4.88 ) was a significant risk factor for OS, while sarcopenia in colon cancer $(\mathrm{HR}=1.79,95 \% \mathrm{CI}$ $=0.96$ to 3.34), colorectal liver metastases $(\mathrm{HR}=0.95$, $95 \% \mathrm{CI}=0.41$ to 2.20 ), extrahepatic cholangiocarcinoma ( $\mathrm{HR}=2.13,95 \% \mathrm{CI}=0.98$ to $\left.4.63 ; I^{2}=30 \%\right)$, hepatocellular carcinoma $(\mathrm{HR}=1.13,95 \% \mathrm{CI}=0.87$ to 1.46$)$, and pancreatic cancer (HR $=2.56,95 \% \mathrm{CI}=0.72$ to $9.07 ; I^{2}$ $=69 \%$ ) was not significant.

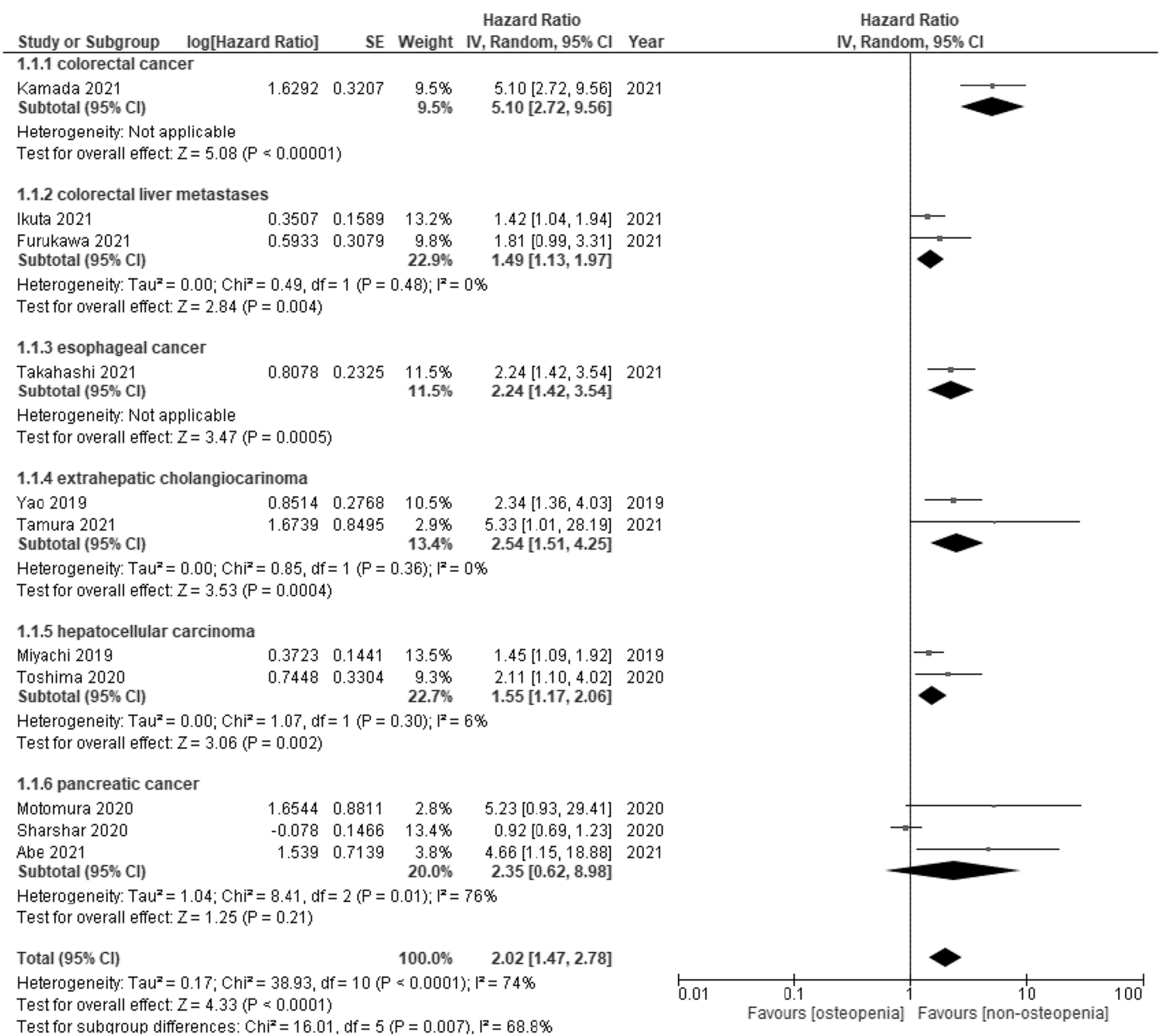

Fig. 2 Forest plot of overall survival for osteopenia 


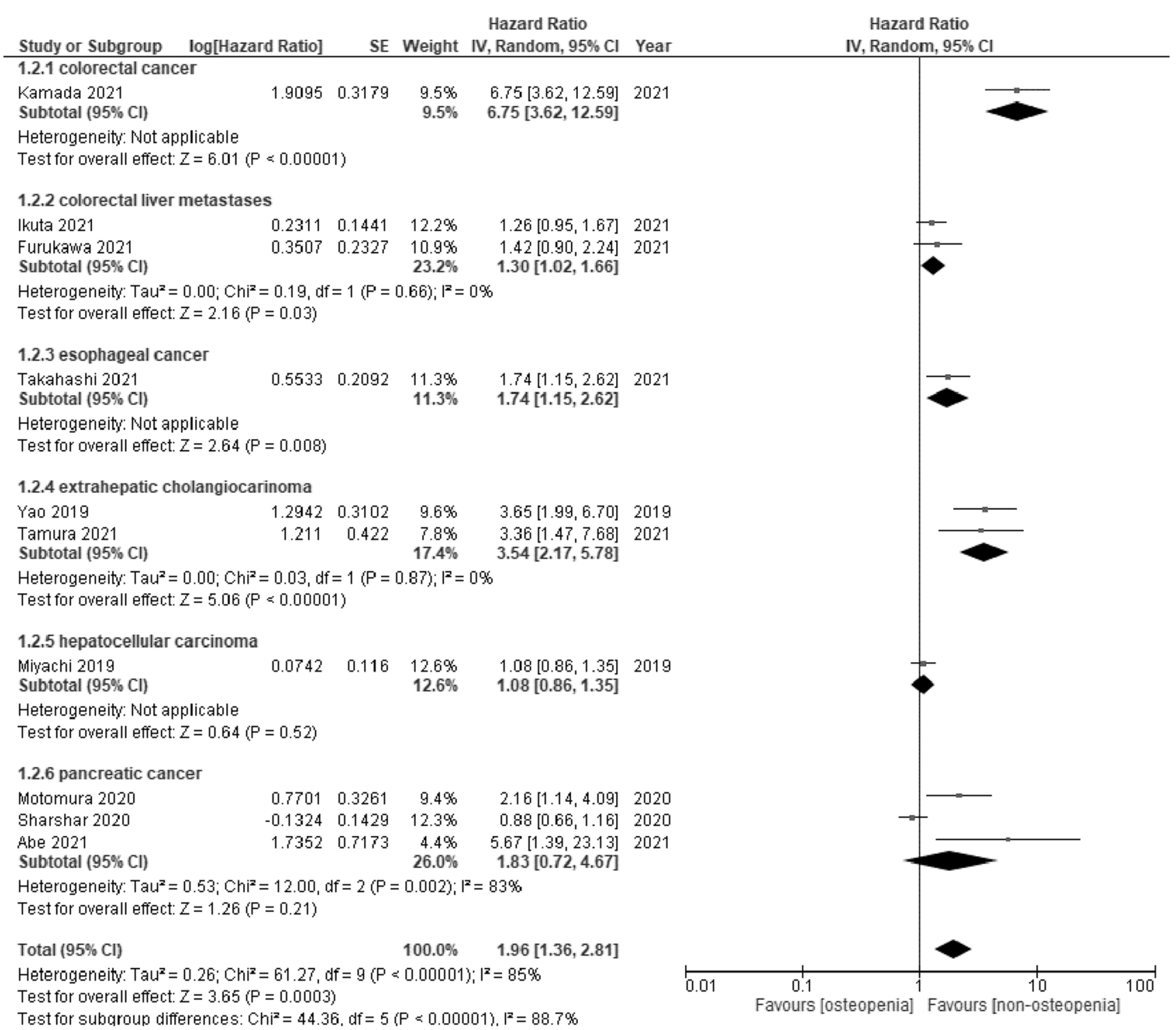

Fig. 3 Forest plot of recurrence-free survival for osteopenia

\section{Publication bias}

Regarding the publication bias of OS and RFS for low BMD, the funnel plots were asymmetric, and the lower left parts were missing, suggesting a potential publication bias (Egger test, $p=0.0083$ and 0.0028 , respectively) (Figs. 5 and 6). Regarding the publication bias of OS for sarcopenia, the funnel plot and Egger test could not be performed because less than 10 trials were found for each outcome according to the Cochrane handbook [15].

\section{Discussion}

Our study demonstrated that low BMD was an independent risk factor for OS and RFS. Sarcopenia was also an independent risk factor for OS. Our first systematic review and meta-analysis on the prognostic value of preoperative osteopenia (indicative of low BMD) may imply the importance of preoperative assessment of osteopenia in patients who underwent resection of digestive tract cancers.

In contrast to the potential implication, the mechanism of the effect of osteopenia on poor prognosis remains to 


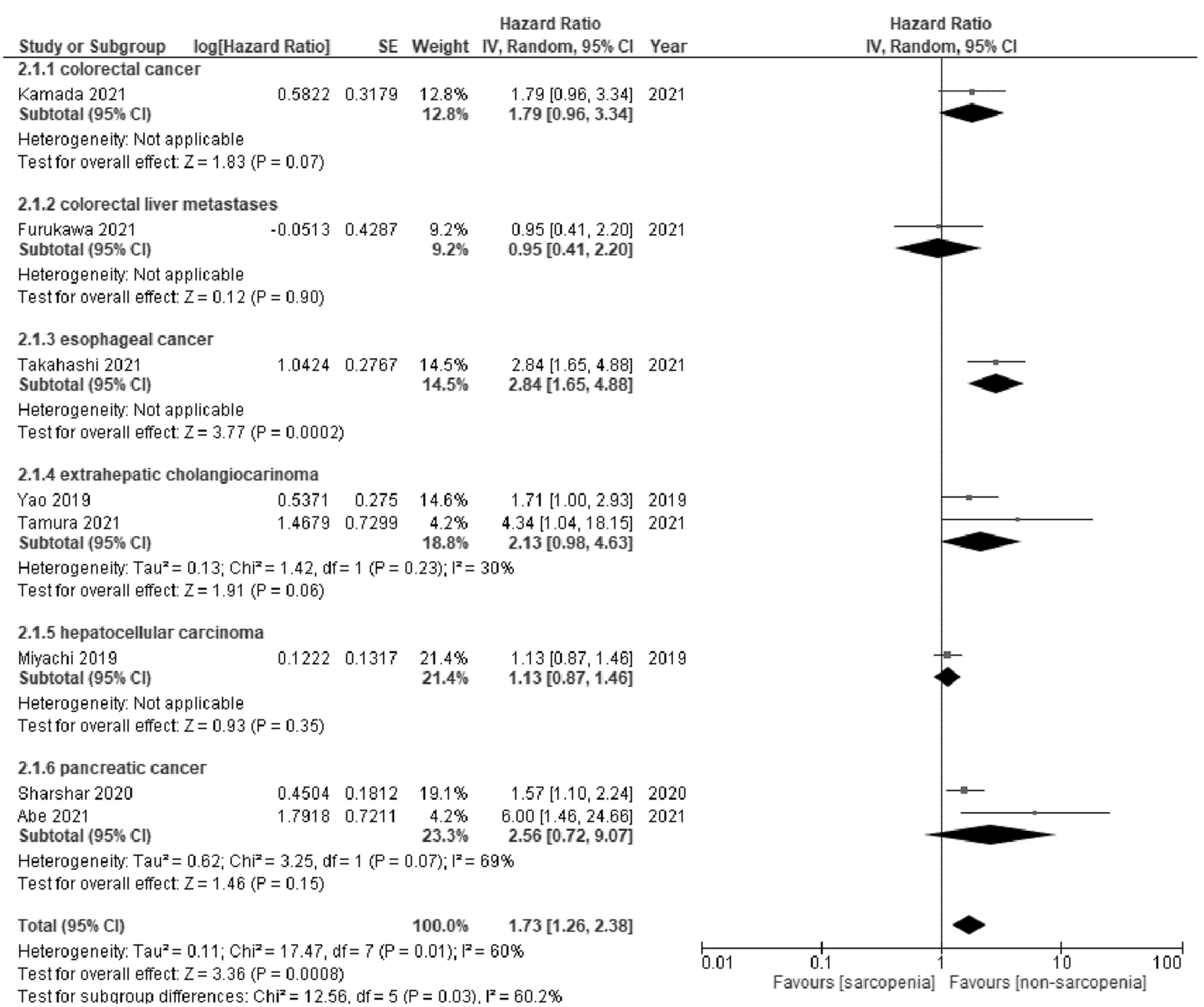

Fig. 4 Forest plot of overall survival for sarcopenia

be elucidated. One possible reason for this is that cachexia could stimulate osteoclast, which causes osteopenia [34]. Osteoclasts are formed and activated by cytokines derived from cancer cells, such as PTHrP, interleukin (IL)-1, IL-6, and IL-8, which activate the RANK/RANKL (receptor activator of NF- $\kappa B$ ligand) signaling mechanism [35]. $\mathrm{NF}-\kappa \mathrm{B}$ is also a possible cause of sarcopenia [34] and a key molecule in the progression of digestive tract cancers [36-38]. Therefore, these findings suggest that osteopenia may be associated with sarcopenia and poor prognosis in digestive tract cancers.

In a previous study, patients who received neoadjuvant chemoradiotherapy tended to have reduced BMD levels [19]. However, in the studies included in this review, preoperative radiation therapy was not performed, and neoadjuvant chemotherapy did not affect prognosis $[25,26,29,30]$. This review found the relationship between osteopenia and prognosis to be comparably high (i.e., HR > 2); however, the reasons for this relationship remain unclear. As there may be hidden factors apart from chemotherapy and/or radiotherapy, this relationship merits further investigation.

To date, we have found one systematic review showing the significance of low BMD on breast cancer among various cancers [36]. In breast cancer, we consider the influence of menopause and hormone replacement therapy, which affects in vivo estrogen levels, on prognosis; this is to some degree associated with BMD [37, 38]. As digestive cancers are not affected by estrogen, the influence of low BMD on prognosis was directly evaluated in this review.

The poor prognosis of osteopenia in patients with digestive tract cancers is debatable in relation to sarcopenia. In a previous study, osteopenia was an independent risk factor 
Fig. 5 Funnel plot of overall survival for osteopenia
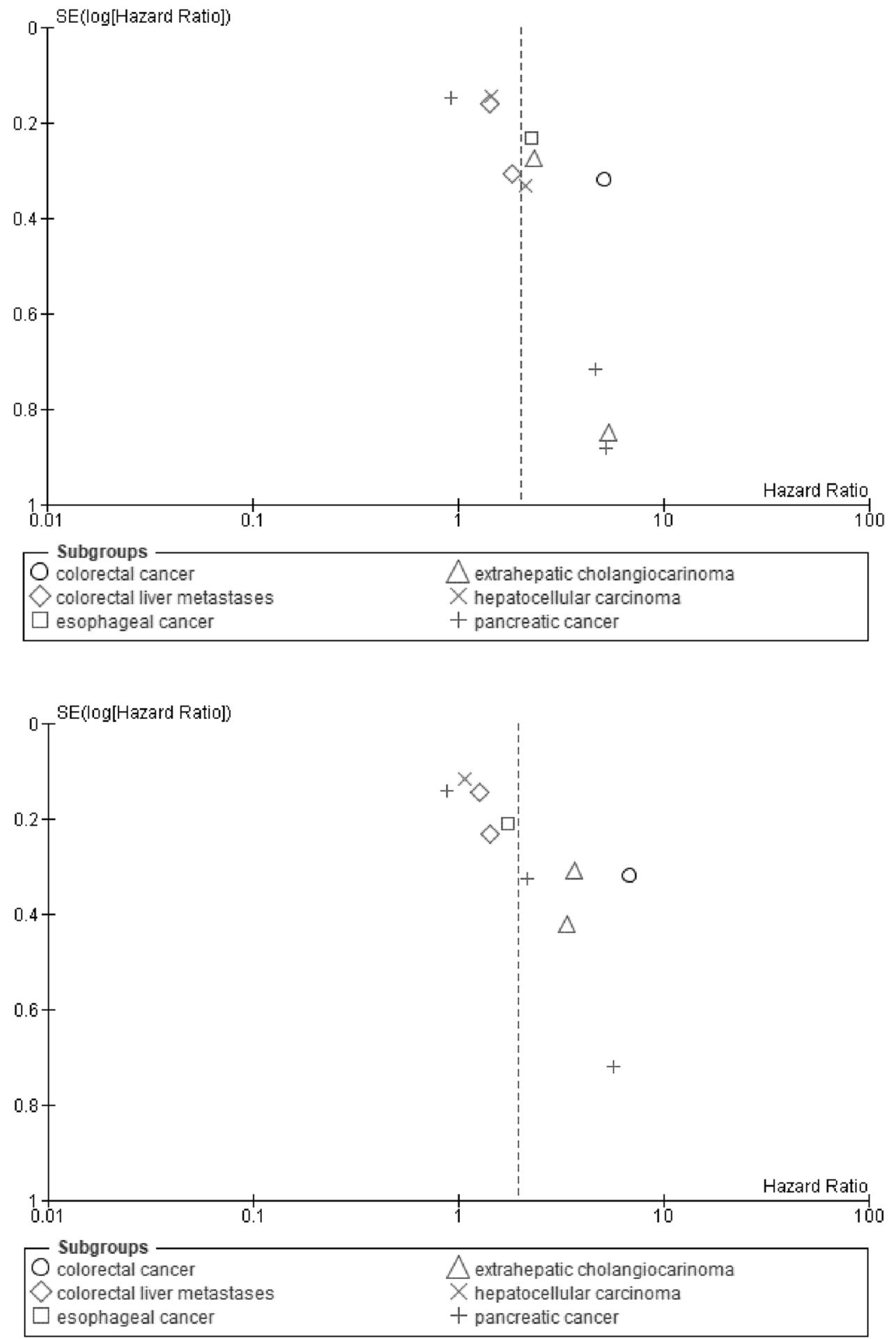

Fig. 6 Funnel plot of recurrence-free survival for osteopenia for poor prognosis that precedes sarcopenia [7]. In our review, osteopenia was associated with lower OS compared to sarcopenia in all cancers except pancreatic cancer. Differences in cutoff values of osteopenia, sex, and age may be a reason why osteopenia was not identified as a risk factor for OS in pancreatic cancer [39]. However, the subgroup analysis could not examine the results separately for each sex or age because the number of studies for each cancer included in this review was small. Our results indicate that osteopenia may be a poor prognostic factor that precedes sarcopenia; however, further studies are warranted to investigate in detail the relationship between osteopenia and sarcopenia on the prognostic values in patients with digestive tract cancers. 
Methods to improve osteopenic conditions include exercise and oral nutritional support [40]. Exercise, especially progressive resistance training, weight-bearing impact activities or multimodal programs, is an important approach to manage cancer-related bone loss [41, 42]. Preoperative nutritional support, especially calcium intake through diet, supplements, or both and vitamin D supplementation, may prevent osteopenia because vitamin D deficiency is a significant risk factor for bone density loss [18]. However, the level of evidence supporting these recommendations is limited.

A potential publication bias was detected in OS for osteopenia. However, in accordance with the PRISMA statement [11], protocols were searched using clinical trial registry systems (ClinicalTrials.gov and ICTRP) to examine unpublished trials, which were not identified. Furthermore, we contacted the original authors and searched for potential unpublished studies whenever possible.

This study has several limitations. First, the number of studies for each cancer included in this review was small. However, a rigorous methodology was adopted, including a comprehensive search, according to the PRISMA statement. Second, DXA, the gold standard for assessing osteopenia, was not available, and the cutoff values for osteopenia differed between studies. DXA scans were not available at all centers, and additional costs were borne by patients, while preoperative CT was available for all preoperative patients with digestive tract cancers and is a simple way to measure BMD. Third, the results of the Japanese studies included in this review may not be applicable to patients with digestive tract cancers in Western countries. Further international multicenter studies are needed to assess the impact of osteopenia on prognosis, because these limitations make the supporting evidence less certain, and drawing valid conclusions is also made more difficult.

\section{Conclusion}

The findings of the present systematic review and metaanalysis indicated that preoperative osteopenia (indicative of low BMD) in patients with digestive tract cancers likely predicted poor prognosis. Considering that osteopenia affected prognosis independently of sarcopenia in each cancer, osteopenia may be an early marker of poor prognostic factors that precede sarcopenia. Further studies are needed to clarify the prognostic impact of osteopenia in patients with digestive tract cancers.

Supplementary Information The online version contains supplementary material available at https://doi.org/10.1007/s11657-022-01060-6.

Acknowledgements We thank Dr. Kenei Furukawa from the Division of Hepatobiliary and Pancreas Surgery Department of Surgery, Jikei
University School of Medicine, and Dr. Hidetoshi Eguchi and Dr. Daisaku Yamada from the Department of Gastroenterological Surgery, Graduate School of Medicine, Osaka University, Dr. Takashi Hotomura from the Department of Pathology, University of Pittsburgh School of Medicine, Pittsburgh Liver Research Center, Dr. Yosuke Miyachi from the Division of Hepato-Biliary-Pancreatic and Transplant Surgery, Department of Surgery, Graduate School of Medicine, Kyoto University, and Toshimi Kaido from the Department of Gastroenterological and General Surgery, St. Luke's International Hospital, for providing us with the detailed information necessary for this study.

Availability of data and material All data analyzed in this study are included in this published article.

Funding This work was supported by JSPS KAKENHI Grant Number JP21K21121.

\section{Declarations}

\section{Conflicts of interest None.}

Open Access This article is licensed under a Creative Commons Attribution 4.0 International License, which permits use, sharing, adaptation, distribution and reproduction in any medium or format, as long as you give appropriate credit to the original author(s) and the source, provide a link to the Creative Commons licence, and indicate if changes were made. The images or other third party material in this article are included in the article's Creative Commons licence, unless indicated otherwise in a credit line to the material. If material is not included in the article's Creative Commons licence and your intended use is not permitted by statutory regulation or exceeds the permitted use, you will need to obtain permission directly from the copyright holder. To view a copy of this licence, visit http://creativecommons.org/licenses/by/4.0/.

\section{References}

1. Siegel RL, Miller KD, Fuchs HE, Jemal A (2021) Cancer Statistics, 2021. CA Cancer J Clin 71:7-33. https://doi.org/10.3322/ caac. 21654

2. Peery AF, Crockett SD, Murphy CC, Lund JL, Dellon ES, Williams JL, Jensen ET, Shaheen NJ, Barritt AS, Lieber SR, Kochar B, Barnes EL, Fan YC, Pate V, Galanko J, Baron TH, Sandler RS (2019) Burden and cost of gastrointestinal, liver, and pancreatic diseases in the United States: update 2018. Gastroenterology 156:254-272. https://doi.org/10.1053/j.gastro.2018.08.063

3. Granieri S, Altomare M, Bruno F, Paleino S, Bonomi A, Germini A, Facciorusso A, Fagnani D, Bovo G, Cotsoglou C (2021) Surgical treatment of gastric cancer liver metastases: systematic review and meta-analysis of long-term outcomes and prognostic factors. Crit Rev Oncol Hematol 163:103313. https://doi.org/10.1016/j. critrevonc.2021.103313

4. Cruz-Jentoft AJ, Bahat $\mathrm{G}$, Bauer J, Boirie $\mathrm{Y}$, Bruyère $\mathrm{O}$, Cederholm T, Cooper C, Landi F, Rolland Y, Sayer AA, Schneider SM, Sieber CC, Topinkova E, Vandewoude M, Visser M, Zamboni M, Writing Group for the European Working Group on Sarcopenia in Older People 2 (EWGSOP2), and the Extended Group for EWGSOP2 (2019) Sarcopenia: revised European consensus on definition and diagnosis. Age Ageing 48:16-31. https://doi.org/ 10.1093/ageing/afy169

5. Su H, Ruan J, Chen T, Lin E, Shi L (2019) CT-assessed sarcopenia is a predictive factor for both long-term and short-term outcomes in gastrointestinal oncology patients: a systematic review and 
meta-analysis. Cancer Imaging 19:82. https://doi.org/10.1186/ s40644-019-0270-0

6. Sepúlveda-Loyola W, Phu S, Bani Hassan E, Brennan-Olsen SL, Zanker J, Vogrin S, Conzade R, Kirk B, Al Saedi A, Probst V, Duque G (2020) The joint occurrence of osteoporosis and sarcopenia (osteosarcopenia): definitions and characteristics. J Am Med Dir Assoc 21:220-225. https://doi.org/10.1016/j.jamda

7. Sharma P, Parikh ND, Yu J, Barman P, Derstine BA, Sonnenday CJ, Wang SC, Su GL (2016) Bone mineral density predicts posttransplant survival among hepatocellular carcinoma liver transplant recipients. Liver Transpl 22:1092-1098. https://doi.org/10.1002/lt.24458

8. Pickhardt PJ, Pooler BD, Lauder T, del Rio AM, Bruce RJ, Binkley N (2013) Opportunistic screening for osteoporosis using abdominal computed tomography scans obtained for other indications. Ann Intern Med 158:588-595. https://doi.org/10.7326/ 0003-4819-158-8-201304160-00003

9. Pinto EM, Neves JR, Teixeira A, Frada R, Atilano P, Oliveira F, Veigas T, Miranda A (2021) Efficacy of Hounsfield units measured by lumbar computer tomography on bone density assessment: a systematic review. Spine (Phila Pa 1976). https://doi.org/ 10.1097/BRS.0000000000004211

10. Hirschfeld HP, Kinsella R, Duque G (2017) Osteosarcopenia: where bone, muscle, and fat collide. Osteoporos Int 28:27812790. https://doi.org/10.1007/s00198-017-4151-8

11. Page MJ, McKenzie JE, Bossuyt PM, Boutron I, Hoffmann TC, Mulrow CD, Shamseer L, Tetzlaff JM, Akl EA, Brennan SE, Chou R, Glanville J, Grimshaw JM, Hróbjartsson A, Lalu MM, Li T, Loder EW, Mayo-Wilson E, McDonald S et al (2021) The PRISMA 2020 statement: an updated guideline for reporting systematic reviews. BMJ 372:n71. https://doi.org/10.1136/bmj.n71

12. Shapiro CL, Van Poznak C, Lacchetti C, Kirshner J, Eastell R, Gagel R, Smith S, Edwards BJ, Frank E, Lyman GH, Smith MR, Mhaskar R, Henderson T, Neuner J (2019) Management of osteoporosis in survivors of adult cancers with nonmetastatic disease: ASCO clinical practice guideline. J Clin Oncol 37:2916-2946. https://doi.org/10.1200/JCO.19.01696

13. Hayden JA, Côté P, Bombardier C (2006) Evaluation of the quality of prognosis studies in systematic reviews. Ann Intern Med 144:427-437. https://doi.org/10.7326/0003-4819-144-6-20060 3210-00010

14. Hayden JA, van der Windt DA, Cartwright JL, Côté P, Bombardier C (2013) Assessing bias in studies of prognostic factors. Ann Intern Med 158:280-286. https://doi.org/10.7326/0003-4819-1584-201302190-00009

15. Higgins JPT, Thomas J (2021) Cochrane handbook for systematic reviews of interventions version 6.2, 2021. Cochrane, 2021. Available online: https://training.cochrane.org/handbook/curre nt. Accessed 9 Aug 2021

16. Guyatt G, Oxman AD, Akl EA, Kunz R, Vist G, Brozek J, Norris S, Falck-Ytter Y, Glasziou P, DeBeer H, Jaeschke R, Rind D, Meerpohl J, Dahm P, Schünemann HJ (2011) GRADE guidelines: 1. Introduction-GRADE evidence profiles and summary of findings tables. J Clin Epidemiol 64:383-394. https://doi.org/ 10.1016/j.jclinepi.2010.04.026

17. Liang KH, Zhang P, Lin CL, Wang SC, Hu TH, Yeh CT, Su GL (2020) Morphomic signatures derived from computed tomography predict hepatocellular carcinoma occurrence in cirrhotic patients. Dig Dis Sci 65:2130-2139. https://doi.org/10.1007/ s10620-019-05915-w

18. Chen CW, Tsai HL, Yeh YS, Lin HL, Huang CW, Chen CF, Chang YT, Lou YT, Wang JY (2013) Osteoporosis self-assessment tool for Asians as a simple risk index of identifying a poor prognosis in women surgically treated for colorectal cancer. J Surg Res 181:242-249. https://doi.org/10.1016/j.jss.2012.06.062

19. Yamada D, Eguchi H, Iwagami Y, Mukai Y, Hashimoto Y, Asaoka T, Noda T, Kawamoto K, Gotoh K, Kobayashi S, Takeda Y,
Tanemura M, Mori M, Doki Y (2017) Patients treated with preoperative chemoradiation for pancreatic ductal adenocarcinoma have impaired bone density, a predictor of distant metastasis. Ann Surg Oncol 24:3715-3724. https://doi.org/10.1245/s10434-017-6040-y

20. Katsube T, Murayama M, Yamaguchi K, Miyaki A, Isohata N, Asaka S, Shiozawa S, Yoshimatsu K, Shimakawa T, Naritaka Y, Ogawa K (2011) Preoperative bone mineral density in gastric cancer patients. Hepatogastroenterology 58:1071-1074

21. Sharma P, Parikh ND, Yu J, Barman P, Derstine BA, Sonnenday CJ, Wang SC, Su GL (2016) Bone mineral density predicts posttransplant survival among hepatocellular carcinoma liver transplant recipients. Liver Transpl 22:1092-1098. https://doi.org/10. 1002/lt.24458

22. Elliott JA, Casey S, Murphy CF, Docherty NG, Ravi N, Beddy P, Reynolds JV, le Roux CW (2019) Risk factors for loss of bone mineral density after curative esophagectomy. Arch Osteoporos 14:6. https://doi.org/10.1007/s11657-018-0556-Z

23. Miyachi Y, Kaido T, Yao S, Shirai H, Kobayashi A, Hamaguchi Y, Kamo N, Yagi S, Uemoto S (2019) Bone mineral density as a risk factor for patients undergoing surgery for hepatocellular carcinoma. World J Surg 43:920-928. https://doi.org/10.1007/ s00268-018-4861-x

24. Yao S, Kaido T, Okumura S, Iwamura S, Miyachi Y, Shirai H, Kobayashi A, Hamaguchi Y, Kamo N, Uozumi R, Yagi S, Uemoto S (2019) Bone mineral density correlates with survival after resection of extrahepatic biliary malignancies. Clin Nutr 38:2770-2777. https://doi.org/10.1016/j.clnu.2018.12.004

25. Motomura T, Uchiyama H, Iguchi T, Ninomiya M, Yoshida R, Honboh T, Sadanaga N, Akashi T, Matsuura H (2020) Impact of osteopenia on oncologic outcomes after curative resection for pancreatic cancer. In Vivo 34:3551-3557. https://doi.org/10.21873/ invivo. 12198

26. Sharshar M, Kaido T, Shirai H, Okumura S, Yao S, Miyachi Y, Iwamura S, Kamo N, Yagi S, Macshut M, Uemoto S (2020) Impact of the preoperative bone mineral density on the outcomes after resection of pancreatic cancer. Surg Today 50:757-766. https://doi.org/10.1007/s00595-019-01954-y

27. Toshima T, Yoshizumi T, Kosai-Fujimoto Y, Inokuchi S, Yoshiya S, Takeishi K, Itoh S, Harada N, Ikegami T, Soejima Y, Mori M (2020) Prognostic impact of osteopenia in patients who underwent living donor liver transplantation for hepatocellular carcinoma. World J Surg 44:258-267. https://doi.org/10.1007/ s00268-019-05206-5

28. Abe K, Furukawa K, Okamoto T, Matsumoto M, Futagawa Y, Haruki K, Shirai Y, Ikegami T (2021) Impact of osteopenia on surgical and oncological outcomes in patients with pancreatic cancer. Int J Clin Oncol. https://doi.org/10.1007/s10147-021-01986-w

29. Furukawa K, Haruki K, Taniai T, Hamura R, Shirai Y, Yasuda J, Shiozaki H, Onda S, Gocho T, Ikegami T (2021) Osteosarcopenia is a potential predictor for the prognosis of patients who underwent hepatic resection for colorectal liver metastases. Ann Gastroenterol Surg 5:390-398

30. Ikuta S, Aihara T, Nakajima T, Kasai M, Yamanaka N (2021) Computed tomography-measured bone mineral density as a surrogate marker of survival after resection of colorectal liver metastases. Ann Transl Med 9(21):10.21037/atm-20-3751

31. Takahashi K, Nishikawa K, Furukawa K, Tanishima Y, Ishikawa Y, Kurogochi T, Yuda M, Tanaka Y, Matsumoto A, Mitsumori N, Ikegami T (2021) Prognostic significance of preoperative osteopenia in patients undergoing esophagectomy for esophageal cancer. World J Surg 45:3119-3128. https://doi.org/10.1007/ s00268-021-06199-w

32. Tamura S, Ashida R, Sugiura T, Okamura Y, Ito T, Yamamoto Y, Ohgi K, Uesaka K (2021) The prognostic impact of skeletal muscle status and bone mineral density for resected distal 
cholangiocarcinoma. Clin Nutr 40:3552-3558. https://doi.org/10. 1016/j.clnu.2020.12.011

33. Kamada T, Furukawa K, Takahashi J, Nakashima K, Nakaseko Y, Suzuki N, Yoshida M, Ohdaira H, Ikegami T, Suzuki Y (2021) Prognostic significance of osteopenia in patients with colorectal cancer: a retrospective cohort study. Ann Gastroenterol Surg 5:832-843 https://10.1002/ags3.12491

34. Sakuma K, Aoi W, Yamaguchi A (2017) Molecular mechanism of sarcopenia and cachexia: recent research advances. Pflugers Arch 469:573-591. https://doi.org/10.1007/s00424-016-1933-3

35. Jones DH, Nakashima T, Sanchez OH, Kozieradzki I, Komarova SV, Sarosi I, Morony S, Rubin E, Sarao R, Hojilla CV, Komnenovic V, Kong YY, Schreiber M, Dixon SJ, Sims SM, Khokha R, Wada T, Penninger JM (2006) Regulation of cancer cell migration and bone metastasis by RANKL. Nature 440:692-696. https://doi. org/10.1038/nature04524

36. Zain NM, Seriramulu VP, Chelliah KK (2016) Bone mineral density and breast cancer risk factors among premenopausal and postmenopausal women a systematic review. Asian Pac J Cancer Prev 17:3229-3234

37. Stewart A, Kumar V, Torgerson DJ, Fraser WD, Gilbert FJ, Reid DM (2005) Axial BMD, change in BMD and bone turnover do not predict breast cancer incidence in early postmenopausal women. Osteoporos Int 16:1627-1632. https://doi.org/10.1007/ s00198-005-1886-4

38. Narod SA (2011) Hormone replacement therapy and the risk of breast cancer. Nat Rev Clin Oncol 8:669-676. https://doi.org/10. 1038/nrclinonc. 2011.110

39. Samelson EJ, Christiansen BA, Demissie S, Broe KE, Louie-Gao Q, Cupples LA, Roberts BJ, Manoharam R, D'Agostino J, Lang T, Kiel DP, Bouxsein ML (2012) QCT measures of bone strength at the thoracic and lumbar spine: the Framingham Study. J Bone Miner Res 27:654-663. https://doi.org/10.1002/jbmr.1482

40. Kiss N, Baguley BJ, Dalla Via J, Fraser SF, Bolam KA, Daly RM (2020) Exercise and nutritional approaches to combat cancer-related bone and muscle loss. Curr Osteoporos Rep 18:291-300. https://doi.org/10.1007/s11914-020-00589-0

41. Pagnotti GM, Thompson WR, Guise TA, Rubin CT (2021) Suppression of cancer-associated bone loss through dynamic mechanical loading. Bone 150:115998. https://doi.org/10.1016/j.bone. 2021.115998

42. Campbell KL, Winters-Stone KM, Wiskemann J, May AM, Schwartz AL, Courneya KS, Zucker DS, Matthews CE, Ligibel JA, Gerber LH, Morris GS, Patel AV, Hue TF, Perna FM, Schmitz KH (2019) Exercise guidelines for cancer survivors: consensus statement from international multidisciplinary roundtable. Med Sci Sports Exerc 51:2375-2390. https://doi.org/10.1249/MSS. 0000000000002116

43. Lee BL, Lee HS, Jung J, Cho SJ, Chung HY, Kim WH, Jin YW, Kim CS, Nam SY (2005) Nuclear factor-kappaB activation correlates with better prognosis and Akt activation in human gastric cancer. Clin Cancer Res 11:2518-2525. https://doi.org/10.1158/ 1078-0432.CCR-04-1282

44. Furukawa K, Uwagawa T, Haruki K, Fujiwara Y, Iida T, Shiba H, Misawa T, Ohashi T, Yanaga K (2013) Nuclear factor $\kappa B$ activity correlates with the progression and prognosis of pancreatic cancer in a mouse model. Surg Today 43:171-177. https://doi.org/10. 1007/s00595-012-0279-5

45. Casimiro S, Vilhais G, Gomes I, Costa L (2021) The roadmap of RANKL/RANK pathway in cancer. Cells 10:1978. https://doi.org/ 10.3390/cells10081978

Publisher's note Springer Nature remains neutral with regard to jurisdictional claims in published maps and institutional affiliations. 